\title{
De los usos de los conceptos de "nación" y la formación del espacio político en el Río de la Plata (1810-1827)
}

\author{
Noemí Goldman y Nora Souto* \\ INSTITUTO DE HISTORIA ARGENTINA Y AMERICANA \\ "DR. E. RAVIGNANI" FACULTAD DE FILOSOFÍA Y LITRAS- \\ UNIVERSIDAD DE BUENOS AIRES/CONICET
}

Análisis de los rasgos fundamentales en la formación de un nuevo espacio político en el Río de la Plata a partir de 1810 .

El vocablo "nación" es el punto de partida para investigar la trama de diversos conceptos sobre el sujeto de soberanía en la elite política ilustrada rioplatense.

$\mathrm{E}$

n este trabajo nos proponemos examinar algunos de los rasgos fundamentales del conflictivo proceso de conformación de un nuevo espacio político en el Río de la Plata a partir de 1810; proceso que revela la coexistencia de tendencias opuestas de creación de soberanías autónomas y de establecimiento de una nación. La riqueza del vocablo "nación", que surge del conjunto de sus empleos durante el periodo $1810-1827$, constituye

* Agradecemos los comentarios y sugerencias a versiones anteriores de este trabajo a Carlos Forment, José Carios Chiaramonte y a los árbitros anónimos de Secuencia. un adecuado punto de partida para investigar las elaboraciones conceptuales en torno al sujeto de la soberanía de la elite política ilustrada rioplatense.

La búsqueda surgió cuando confluyeron distintas inquietudes. Primero habíamos observado que la historiografia rioplatense prestaba excesiva atención a las influencias ideológicas en los discursos y textos de las primeras décadas independientes. Luego, advertimos la atribución de sentidos univocos o contemporáneos a los vocablos políticos significativos del periodo. Finalmente, nos llamó la atención la persistencia de una tesis generada en 
la historiografía romántica que ligó las revoluciones de independencia a una supuesta nacionalidad preexistente. Esta suposición respondía al empeño de los historiadores que pretendian consolidar los débiles estados surgidos del colapso de la monarquía ibérica. Sin embargo, el criterio actual tiende a prescindir de este principio, ${ }^{1}$ y extiende su perspectiva hacia las variadas formas de Estado y hacia las diversas expresiones de identidad política del periodo. ${ }^{2}$

Para responder a estas inquietudes, y al mismo tiempo abrir nuevas perspectivas, elegimos una aproximación desde el análisis de los usos del vocabulario político. En efecto, el estudio de las filiaciones privilegiaba los discursos de los hombres públicos más representativos, y descuidaba el resto de los textos políticos de la época. Nuestra investigación, por el contrario, se basó en una gran variedad de textos de origen diverso: discursos, de-

\footnotetext{
I En una serie de libros la historiografía europea mostró el carácter artificial de las naciones surgidas durante el siglo XIX y la imposibilidad de establecer criterios objetivos para definir la pertenencia a una nación. Véase: Anderson, Imagined, 1983; Gellner, Nation, 1983; Hobsbawm, Nations, 1990.

${ }^{2}$ José Carlos Chiaramonte, en una serie de trabajos, ha revelado las implicancias mayores de la existencia de diversas formas de identidad política -hispanoamericana, rioplatense o argentina y provincial- hacia 1810 , para mejor comprensión de la naturaleza sociopolítica del proceso de independencia rioplatense. Véase del autor mencionado: "Formas", Boletín, 3a. serie, núm. 1, 1er. semestre de 1989, pp. 71-92; Mito, 1992; "Ciudad", Actas, 1992, vol. 1, pp. 101-128. Para una revisión general de esta problemática en el conjunto hispanoamericano, puede verse: Guerra, Modernidad, 1992.
}

cretos, bandos, proclamas, correspondencia, etc. Asimismo, un tratamiento sistemático sobre las relaciones semánticas ${ }^{3}$ del término "nación" permitió descubrir polisemias y deslizamientos de sentido que revelaban una conflictiva coexistencia: la de diferentes concepciones doctrinarias y la de diversas formas de identidad política en el Río de la Plata a comienzos del siglo XIX. Por otra parte, la incorporación de otros textos permitió comprender lo que podemos designar como uso social de los vocablos políticos. Los autores de estos textos no sólo eran los dirigentes políticos de Buenos Aires, sino corporaciones tales como los cabildos de otras ciudades, jefes militares, corresponsales anónimos; si bien todos ellos, integrantes de una elite política.

Al respecto, merecen mención particular las características de conformación y de análisis de nuestro corpus documental. En primer lugar, se realizó un relevamiento de la totalidad de los usos del término elegido en la prensa política. ${ }^{4}$ En segundolugar, dada

\footnotetext{
3 Para una lectura crítica de las diferentes perspectivas metodológicas y debates acerca de la relación entre análisis del discurso e historia, pueden verse: Goldman, Discurso, 1989; Schöttier, "Historians", History, 1989, pp. 37.65; Goldman, Historia, 1992; Guilhaumou, "Propos", Langage, num. 59, 1992, pp. 5-38; Guilhaumou, Maididier, Robin, Discours, 1994; Baker, Chartier, "Dialogue", Politix, núm. 26, 1994, pp. 5-22.

${ }_{4}^{4}$ Para este estudio recurrimos al examen de los siguientes periódicos: la Gaceta de Buenos Aires (1810-1821), El Redactor del Congreso Nacional (1816-1820), el Argos de Buenos Aires (1821-1825), El Argentino (1824-1825), El Mensajero Argentino (1825-1827). Y a los de-
} 
la magnitud de este corpus, se optó porcombinar dos aproximaciones: una lexicológica ${ }^{5}$ otra conceptual. La lectura de la documentación nos sugirió dividir el periodo en dos etapas, de acuerdo a una serie de acontecimientos orientadores acerca de la constitución del Estado en diversas direcciones.

\section{PERIODIZACIÓN Y ESPACIO POLÍ́TICO}

Previamente a nuestro análisis es conveniente determinar el espacio geográfico y las divisiones político-administrativas del periodo comprendido en este estudio. ${ }^{6}$ El virreinato del Río de la Plata comprendía los territorios de los actuales estados de Argentina, Paraguay, Bolivia y Uruguay. Iniciado el proceso revolucionario hacia 1810 , Paraguay se convirtió en Estado inde. pendiente en 1811; Bolivia-denominado en la época, Alto Perú- permaneció en manos de los realistas entre 1811 y 1825 . Uruguay, en ese entonces llamado Banda Oriental, fue teatro de continuos conflictos y ocupacio-

bates del Congreso Constituyente de 1824/27. Agradecemos a la licenciada Silvia Ratto el fichado de una parte de este material.

${ }^{5}$ Para esta aproximación nos inspiramos en la ya clásica corriente francesa de estudios de léxico sociopolítico. Entre otros pueden consultarse la revista Mots y Equipe " 18 ème et Révolution", Dictionnaire, 1985-1991, además de los citados en la nota 2.

6 Véanse mapas adjuntos. Mapa 1: Organización político-administrativa de acuerdo a la Real Ordenanza de Intendentes de 1782. Mapa 2: Provincias del Río de la Plata a partir de 1820, mapas extraídos de Ravignani, Clave, s.a. nes de las fuerzas de Buenos Aires, del imperio luso-brasilero, de los realistas $y$ de los patriotas orientales que respondían a Artigas.

El nombre de Provincias Unidas del Río de la Plata o del Sud surgió en 1810, cuando la Primera Junta revolucionaria de Buenos Aires convocó a los cabildos del interior a enviar representantes a la capital.

En cuanto a organización administrativa, la Revolución de Mayo heredó el sistema de intendencias que España implantó en el Río de la Plata en $\mathbf{1 7 8 2}$. De 1810 a 1820 la revolución reavivó, en gran parte, viejos conflictos jurisdiccionales entre los pueblos subalternos y las capitales de provincias. Así, debe señalarse la necesidad de distinguir entre los intentos de separación de pueblos respecto de las capitales de provincia anteriores a 1820 , y los movimientos autonomistas del 20 , en el sentido de que los primeros no implicaban una reforma del orden administrativo intendencial ni una ruptura con los esfuerzos de unidad emprendidos por el gobierno central, sino un deseo de los pueblos subalternos de eliminar su dependencia de las ciudades cabecera de intendencia.

El periodo comprendido en nuestro estudio puede organizarse en dos etapas. La primera cubre los años iniciales de la revolución-conocida como Revolución de Mayo-, que se caracterizó por la existencia de un gobierno centralizado en Buenos $\mathrm{Ai}$ res. Su acción política estuvo dominada, por una parte, por los vaivenes de la guerra de independencia y por la otra, por los intentos fallidos de organización constitucional republicana 
del antiguo virreinato. ${ }^{7}$ Es importante señalar asimismo que el Río de la Plata no envió diputados a las Cortes de Cádiz y su constitución nunca fue aplicada en este territorio.

La segunda etapa se inicia con la caída del Directorio que implicó la desaparición de un gobierno centralizado del espacio territorial rioplatense en 1820. A partir de ese momento se establecieron gobiernos autónomos en las antiguas ciudades con cabildo -sin la antigua distinción entre pueblos subalternos y ciudades cabeceras-, desde las cuales se definirán nuevos espacios soberanos llamados "provincias" que alcanzarán en el futuro diversos grados de desarrollo estatal. ${ }^{8}$ Por medio de diferentes instrumentos legales (constituciones, reglamentos o leyes), cada una de estas provincias ejercerá una serie de atributos soberanos, tales

${ }^{7}$ Entre 1810 y 1820 se realizaron dos intentos constituyentes: la convocatoria de la Asamblea General Constituyente entre los años 1813 y 1815 , y la reunión de un Congreso Constitu. yente entre 1816 y 1820 , cuya principal obra fue la declaración de la independencia de las pro. vincias del Río de la Plata. En el primero no llegó a elaborarse un texto constitucional, mientras que en el segundo la constitución proclamada no fue aceptada por las provincias.

${ }_{8}^{8}$ Para el caso rioplatense corresponde destacar la interpretación de José Carlos Chiaramonte, según la cual el surgimiento del Estado autóno. mo provincial no es producto de la disgregación de una nación preexistente, sino un punto de partida de una organización político estatal, sobre la única base social existente en el periodo: la ciudad y su campaña. Chiaramonte, "Cuestión", en Palacios (comp.), Uniclad, 1983, pp. $51-85$ e ibid. "Federalismo", en Carmagnani, $\mathrm{Fe}$ deralismos, 1993, pp. 81-127. A partir de 1820 se formaron trece provincias a las que se sumó en 1834 ta de Jujuy desprendida de la jurisdicción de Salta. como el manejo de las finanzas públicas, el establecimiento de aduanas interiores, la emisión de moneda, la administración de justicia.

En esta etapa se llevó a cabo una nueva tentativa de organización constitucional con la reunión de un Congreso General Constituyente entre 1824 y $1827,{ }^{9}$ años en que adquirieron relevancia los sucesos relacionados con la Banda Oriental, y el posterior estallido de la guerra con el Brasil (1825-1828); ambos acontecimientos estimularon la vertebración de un discurso sobre la nación. Por otra parte, el establecimiento por ley del Congreso, de un poder ejecutivo permanente (1826-1827) encarnado en la figura de Bernardino Rivadavia, procuró sin éxito crear un Estado-nación en el Río de la Plata.

\section{La nación en los orígenes de la revolución}

Creada por un decreto de la Junta de Gobierno, la Gaceta de Buenos Aires se constituyó no sólo en un medio de difusión sino en el instrumento de propaganda del gobierno revolucionario. Cumplió así múltiples funciones al informar y difundir la opinión política de las elites porteñas entre la plebe urbana de Buenos Aires y el conjunto

${ }^{9}$ Luego del fracaso de este último intento constitucional de la primera mitad del siglo XIX, las provincias rioplatenses continuaron su desarrollo independiente hasta la firma del Pacto Federal de 1831. Por este pacto se organizaron bajo la forma de una laxa confederación que perdura hasta la aprobación de la constitución de 1853, que fundó el Estado federal argentino. 
Mapa 1

Organización político-administrativa de acuerdo a la Real Ordenanza de Intendentes de $\mathbf{1 7 8 2}$

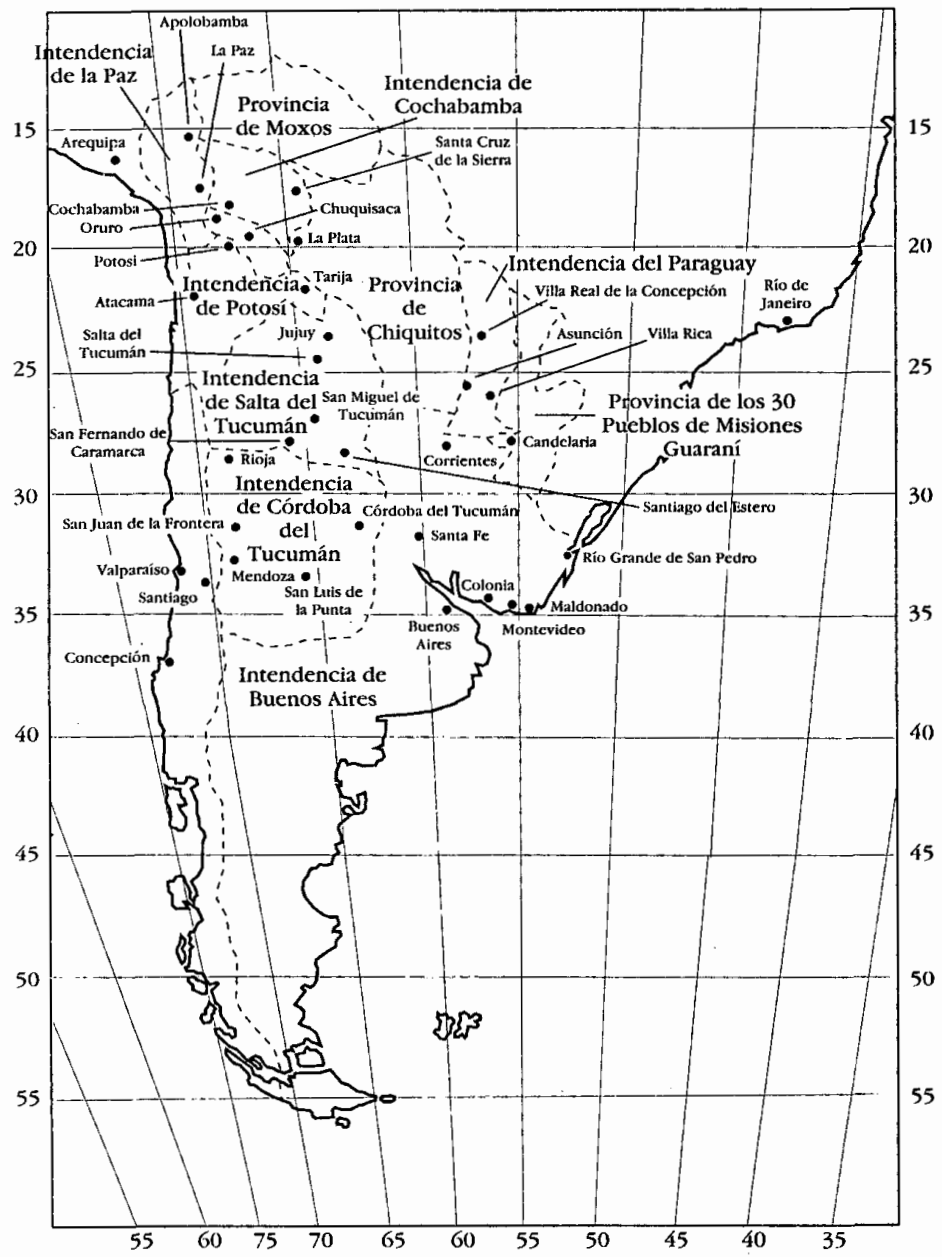

FORMACIÓN DEL ESPACIO POLÍTICO 
MAPA 2

Provincias del RÍo de la PIata, 1820

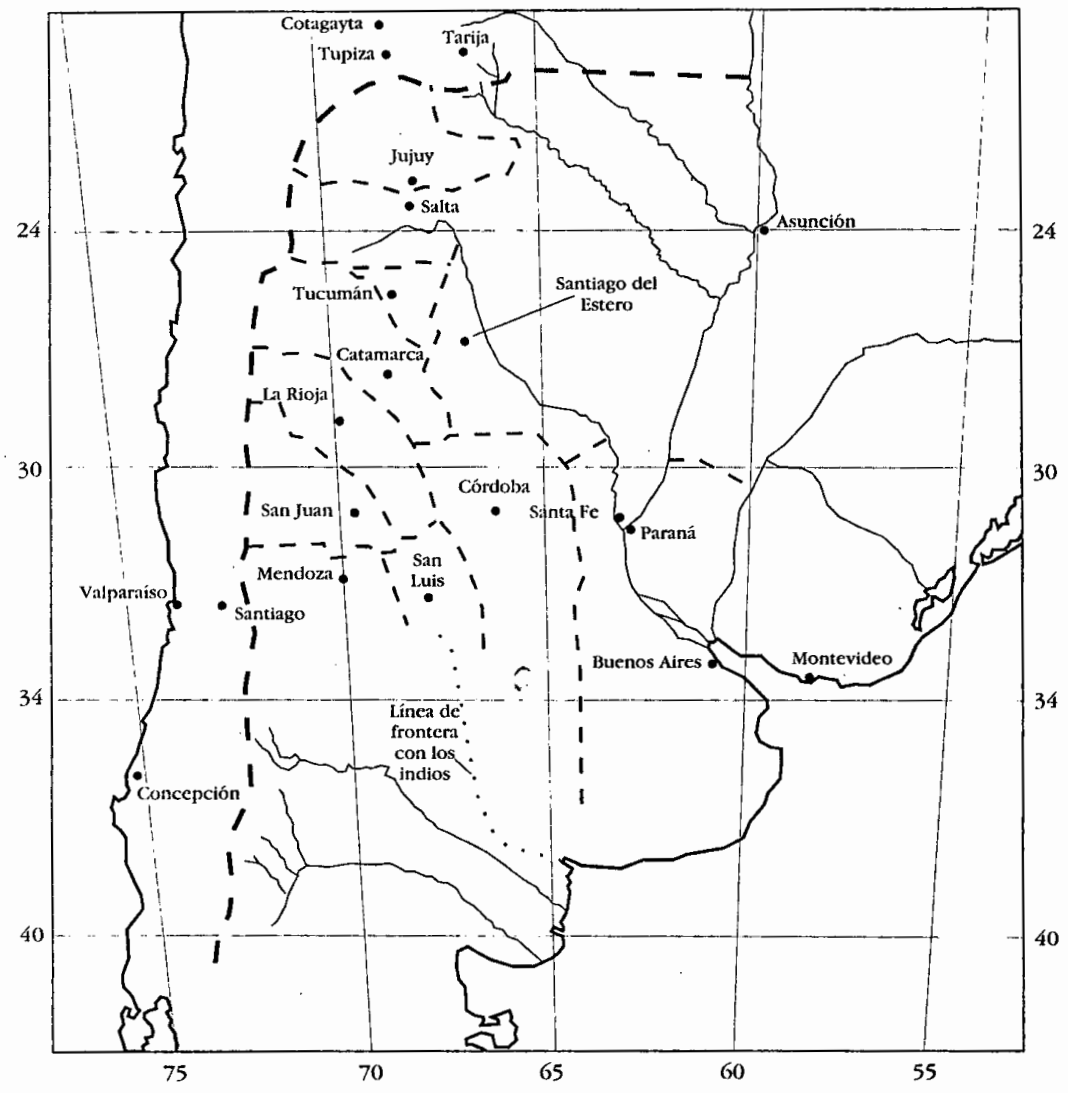


de los pueblos del interior del virreinato. Testimonio de ello es la publicación de los decretos de la Junta, bandos del Cabildo, o informes redactados por los jefes del ejército revolucionario junto a artículos de intención didáctica, escritos por miembros del grupo ilustrado, como Mariano Moreno o Bernardo de Monteagudo. ${ }^{10}$

El relevo sistemático de este material constituye la base para construir las redes semánticas del vocablo nación durante el periodo 1810-1813. Con este tratamiento aspiramos tanto a trascender el examen del discurso de un individuo en particular, 'como a desplegar los "usos" (sus ambigüedades y sus referentes) más habituales de aquel vocablo en esta coyuntura clave. 11

El análisis ha revelado que los usos más frecuentes del vocablo remiten, por una parte, al origen o lugar de nacimiento y, por la otra-como veremos- al sujeto que encarna la soberanía. Es bien conocida la antigüiedad de la primera acepción que, además de remontarse al medioevo, figura en primer término en las ediciones del Diccionario de la Real Academia Española correspondientes al siglo XVII y comienzos del XIX. Tampoco sor-

${ }^{10}$ Cabe recordar que Mariano Moreno fue secretario de Guerra y Gobierno de la primera junta revolucionaria, mientras Bernardo Monteagudo fue un activo promotor de las ideas revolucionarias e independentistas de los primeros años de la revolución. Asimismo ambos fueron redactores del primer periódico político del Río de la Plata, la Gaceta. Goldman, Historia, 1992.

"Para un análisis más detallado de las redes semánticas del vocablo nación entre 1810 y 1813 véase: Souto, "Nación", 1990. prende que se utilice para designar al sujeto de imputación del poder. Es por ello que nuestro esfuerzo se ha centrado en descubrir las nociones que surgen de los empleos del vocablo nación en esta segunda acepción, que traduce tanto un espacio político concreto como las elaboraciones que genera la elite en sus discursos sobre un posible espacio político "nacional".

Las asociaciones lexicales muestran que paralelamente al término nación existen otros vocablos como pueblos (ciudades con ayuntamiento), provincias (las intendenciales), América o los americanos, que no entran en contradicción ni rivalizan con aquél. El hecho de que nación no sea vocablo único ni excluyente para encarnar la fuente de soberanía, sugiere que en esa época no era descabellado el reconocimiento de la natural legitimidad de otras entidades - "los pueblos"para actuar como soberanos. Sin embargo, ello no impide que se admita, a su vez, que estos pueblos -hasta la declaración de la independencia en 1816-integran el sujeto soberano, nación española.

Por otra parte, el examen de las acciones verbales pone al descubierto que sus protagonistas son mayoritariamente "los pueblos", "las provincias", "nosotros", "nuestro/el gobierno", "el congreso", 12 mientras que "nación" aparece como sujeto pasivo.

En efecto, la circular del 27 de mayo de 1810 -expedida por la Junta Provi-

12 Véase por ejemplo: Gaceta, 24 enero 1811 , t. 2., p. 70 y 27 diciembre 1811, t. 3, p. 71 . Los números de las páginas indicadas corresponden a los de la edición facsimilar. 
sional Gubernativa- invoca la doctrina de la retroversión de la soberanía a los pueblos en virtud del cautiverio del monarca, para justificar su instalación en la ciudad de Buenos Aires. Y, asimismo, encomienda el envío de un diputado por cada ciudad o villa, que debía incorporarse a la Junta apenas arribara a la capital, "para que así se hagan de la parte de confianza pública que conviene al mejor servicio del rey y gobierno de los pueblos". ${ }^{13}$

Los sujetos políticos capaces no sólo de actuar sino de hacerlo legítimamente son, por el derecho que se invoca, los pueblos. Y son estos mismos sujetos los que vuelven al primer plano cuando entre los equivalentes de "nación" hallamos expresiones como "nuestros pueblos", "pueblos", "patria", "estas provincias" y "estado".

La presencia constante de estos vocablos nos sugiere que el sentido predominante de "nación" en esos años es el de una entidad producto del agregado de "pueblos". Nos hallamos aquí claramente frente a un sujeto soberano que deriva su poder de la suma de soberanías territoriales -concebidas como comunidades de antiguo régimen-y no de una soberanía única $e$ indivisible, tal como lo entiende la doctrina liberal. En efecto, no se trata de un sujeto ideal y abstracto, fruto de la necesidad de resolver el problema de su representación, sino de un sujeto concreto que, además, se distingue por un acentuado carácter territorial.

13 Circular de la Junta Provisional Gubernativa a los pueblos del virreinato, 27 mayo $1810 \mathrm{en}$ Senado, Biblioteca, 1966, t. xvil, p. 16141.
El pensamiento moderno, en particular en su vertiente democrática aflora, no obstante, en curiosa amalgama junto al concepto comentado. Y no es casual que se manifieste en Mariano Moreno, miembro radical de la elite revolucionaria, tildado de "jacobino" por sus contemporáneos. ${ }^{14}$ Es interesante observar cómo en el siguiente texto, Moreno emplea dos expresiones de distinta índole como equivalentes de nación:

Supongamos en Fernando VII, un príncipe en el pleno goce de sus derechos; $y$ en nuestros pueblos una nación con derechos a todas sus prerrogativas imprescriptibles: demos a cada uno de estos dos extremos toda la representación, toda la dignidad que les corresponde; y mirando a un lado dos millones de hombres congregados en sociedad, y al otro un monarca elevado al trono por aquéllos, obligado a trabajar en su felicidad, e impedido de ejecutarla por haberlo reducido a cadenas un usurpador, preguntemos si la felicidad de la nación queda comprometida, porque trate de establecer una constitución, que no tiene, y que su rey no puede darle. ${ }^{15}$

Con la primera mención el secretario de la Primera Junta se acerca al empleo mencionado más arriba: nación como reunión de pueblos, mientras que la segunda se aproxima a la noción rousseauniana de pueblo.

Otra de las características de estos primeros años revolucionarios es la

${ }^{14}$ Goldman, Discurso, 1989, e tbid., Historia, 1992.

${ }^{15}$ Gaceta, 15 noviembre 1810 , t. 1, p. 615. Cursivas nuestras. 
indefinición del real ámbito espacial al que se alude con el vocablo "nación". En este sentido se aprecia que aquél puede remitir tanto a la nación española -integrada ya por el conjunto de territorios pertenecientes a la corona, ya por los de la península con exclusividad- como a la nación americana, que a su vez puede reunir a la totalidad de los pueblos y provincias americanos como a los del ex virreinato del Río de la Plata. Por su parte, la expresión "nación argentina" es completamente desconocida en este periodo, mientras que el empleo del adjetivo "argentino(a)" no difiere del ya señala. do por Ángel Rosenblat. ${ }^{16}$ Limitado prácticamente en sus orígenes al lenguaje poético o declamatorio, "equivale a rioplatense o bonaerense en un sentido muy general, e incluía también al español". ${ }^{17}$

José Carlos Chiaramonte, al estudiar las formas de identidad colectiva en el Río de la Plata colonial, llamó la atención - retomando a Rosenblatsobre la particularidad del surgimiento del término "argentino" en el vocabulario político de fines del periodo colonial:

Mientras argentino surge en un impulso de regionalismo integrador dentro

\footnotetext{
${ }^{16}$ Rosenblat, Nombre, 1964. El nombre de la Argentina - nos dice Rosenblat-nace de una latinización: argentino (del latín argentum, plata) empezó por ser un adjetivo poético. En efecto, cuando Martín del Barco Centenera pu. blica en Lisboa, 1602, su célebre relación poética de la conquista, La Argentina, es sólo el nombre del poema. En su poema no se encuentra aún ni el gentilicio ni el nombre moderno del país.

17 Jbid., p. 45.
}

del mundo hispano, español americano surge como una forma de identidad que, aun en el caso en que se la asuma también como una forma de integración en lo hispano, denuncia que su génesis es la oposición a lo español. ${ }^{18}$

Más aún, este término que en sus inicios designa sólo a la ciudad de Buenos Aires y su entorno, terminará expandiéndose hasta abarcar el resto del territorio del virreinato en virtud de una pretendida relación de posesión. ${ }^{19}$

Ahora bien, la reunión en 1813 del primer congreso general de las Provincias del Río de la Plata reactualiza el problema de la constitución del Estado. Esta asamblea en la cual predomina la tendencia radical de la revolución, decreta la libertad de prensa, la libertad de vientre, la extinción del tributo, la mita, el yanaconazgo, y el servicio personal; la supresión de los títulos y signos de nobleza; y la eliminación de los mayorazgos. Pero ni la independencia es declarada ni ninguno de los proyectos de constitución propuestos serán aprobados. El temor que aporta una cada vez más cercana restauración monárquica en España, junto a las conflictivas relaciones con la Banda Oriental, terminan por paralizar las iniciativas renovadoras de la asamblea. Es en esta oportunidad cuando se realiza el primer intento por instaurar el concepto liberal de nación a partir de una moción de Alvear respecto del carácter de la representación que debían revestir los diputados. En la formulación del decreto correspon-

18 Chiaramonte, "Ciudad", Actas, 1992, vol. 1, p. 116.

19 Ibid., p. 110. 


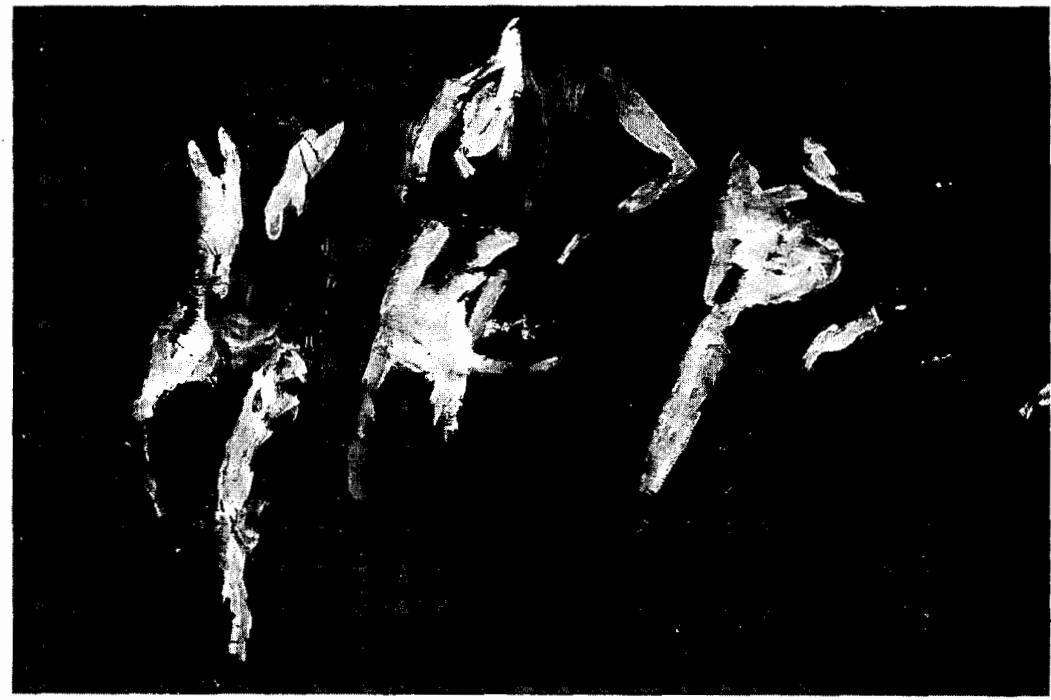

diente a esta moción se hace explícito el rechazo al mandato imperativo que subyace en las instrucciones que traía cada representante. ${ }^{20}$ Los diputados de las Provincias Unidas deberán ser considerados como diputados de "la nación en general", sin perder por ello la denominación del pueblo al que deben su nombramiento.

Sin embargo, resulta de interés detenerse en el comentario del redactor de la asamblea en relación con el decreto:

En virtud de este soberano decreto es indudable que los representantes del pueblo, no pueden tener otra mira que

${ }^{20}$ Ravignani, Asambleas, 1937, t. 1, p. 21 (8 de marzo de 1813). la felicidad universal del Estado, y la de las provincias que los han constituido, sólo en cuanto aquélla no es sino una suma exacta de todos los intereses particulares. $Y$ aunque por este principio es puramente hipotética la contradicción del interés parcial de un pueblo con el común de la nación, resulta sin embargo que en concurso de ambos, éste debe siempre prevalecer, determinando en su favor la voluntad particular de cada diputado considerado distributivamente. 21

Si bien se sostiene en este fragmento que los diputados representan a la nación, entendida como "el todo de las Provincias Unidas", no se abandona la idea ya comentada de nación

${ }^{21}$ Ibid. Cursivas nuestras. 
como "suma exacta de todos los intereses particulares". Más aún, el redactor advierte de la posibilidad de una contradicción en los hechos "entre el interés parcial de un pueblo con el común de la nación". Así, la insistencia en señalar la preeminencia del interés nacional muestra que no es evidente para los pueblos ni para sus diputados, que éste deba prevalecer sobre sus intereses particulares.

En suma, la nación que se concibe hacia 1810 en el Río de la Plata exhibe un aspecto concreto y territorial, donde la reunión de sus componentes (pueblos y provincias) no es más que la suma de los mismos. Sin embargo, estos rasgos no parecen ser exclusivos del Río de la Plata, los encontramos asimismo en las argumentaciones de los diputados americanos a las Cortes de Cádiz. ${ }^{22}$ En este caso se observó que esta concepción derivaba de la combinación de premisas doctrinales de diferente origen. ${ }^{23}$ Pero la ruptura definitiva e irreversible del vínculo con la corona española que significó la declaración de la independencia en 1816, hace desaparecer parte de esta ambigüedad de los referentes asociados a "nación": a partir de ese momento "nación" se asocia en forma predominante a "Río de la Plata". 1983.

22 Véase Varela Suanzes-Carpegna, Teoría,

${ }^{23}$ Ibid., pp. 222-223. Según Varela, estas premisas doctrinales se inspiraron en el dogma de la soberanía popular de Rousseau, pero también en el pensamiento escolástico y del iusnaturalismo germánico. Corresponde destacar asimismo que el sustrato territorialista se vincula con las tradiciones y los principios del Derecho de Indias.

\section{Nación e independencia}

La continuidad de la guerra contra los españoles y la intransigencia de Fernando VII frente a las aspiraciones independentistas de algunas de sus antiguas colonias, tornan imposible una vuelta al pasado en el Río de la Plata. Este viraje provocará modificaciones en el discurso: si antes el referente del vocablo "nación" era polisémico, ahora aparece con claridad que alude a las denominadas Provincias Unidas del Río de la Plata. El Congreso - reunido desde principios de 1816-declara el9 de julio la independencia de dichas provincias de la corona española. Al respecto la Gaceta comenta que aqueIla proclamación eleva a los "pueblos argentinos [...] al rango y preeminencia de nación independiente". ${ }^{24}$ Por ello, si bien la idea de nación como agregado de pueblos sigue vigente, es más frecuente asociar el uso del voca. blo a Estado.

En esta etapa los redactores de la Gaceta evidencian un verdadero empeño por sostener la existencia de un nuevo Estado. La libertad, la independencia y la capacidad para erigir instituciones propias son los tópicos preferidos para justificarlo, mientras que se dejan momentáneamente de lado argumentaciones doctrinales de tipo pactista.

La libertad y aun la calidad de Estado independiente se hacen remontar a 1810 , de allí que el 25 de mayo sea calificado como "la más digna, la más ilustre, la más amada de los corazones patriotas entre todas las fiestas nacio-

${ }^{24}$ Gaceta, 21 noviembre 1816, t. 4, p. 623. 
nales". ${ }^{25} \mathrm{Al}$ respecto, es interesante llamar la atención sobre la elección del 25 de mayo de 1819 como fecha de jura de la constitución elaborada por el Congreso Constituyente. La coincidencia manifiesta de alguna manera la intención de presentar el texto constitucional como el punto culminante del camino iniciado en 1810 . Junto a éste, la celebración oficial de las victorias militares brinda también la ocasión para afirmar la independencia y solidez del nuevo Estado. ${ }^{26}$ En este mismo sentido se invoca el desarrollo de las instituciones. ${ }^{27}$

Por otra parte se manifiesta la voluntad de lograr el reconocimiento externo de las Provincias Unidas en el rango de nación, ${ }^{28}$ apoyada por parte de la

25 Ibid., 27 mayo 1815, t. 4, p. 273.

26 "El Congreso de las Provincias Unidas en Sudamérica penetrado altamente de las ventajas que ha reportado a la nación en las célebres victorias de Chacabuco y Maipo en el territorio de Chile en los años pasado y presente por el ejército unido de los Andes a las órdenes del general en jefe don José de San Martín sobre los ejércitos españoles [...] y deseando manifestar a nombre de la nación que representa el justo reconocimiento que es debido al genio y a la virtud, ha venido en decretar y decreta lo siguiente." Gaceta, 13 mayo 1818, t. 5, p. 386.

27 "Ascender de la condición degradante de una colonia oscura a la jerarquía de una nación; dictarse sus propias leyes; elegir su forma de gobierno; imponerse sus contribuciones; tener cerca de sí y en su propio seno a la Suprema Magistratura." Gaceta, 27 mayo 1815, t. 4, p. 273.

${ }^{28} \mathrm{El}$ redactor de un artículo sobre la estabilidad de las instituciones se pregunta: "Entrando al año décimo de nuestra libertad, preguntamos a las naciones si las pruebas que hemos dado de virilidad en los años anteriores no nos hacen dignos de ser admitidos a su rango", Gaceta, 6 enero 1819 , t. 5 , p. 571 . prensa política extranjera que tiende a considerar a las ex colonias como sujetos de derecho internacional. ${ }^{29}$ Pero ¿cómo está representada esa nación?

En el debate sobre la representación en el ámbito del Congreso de 1816 , se reconoce la preferencia de los pueblos por el gobierno autónomo, aspecto fundamental que inclina a muchos de ellos hacia el "federalismo" o sistema "de provincias o estados confederados". ${ }^{30}$ Es por ello que El Redactor del Congreso Nacional, a pesar de manifestarse en favor del sistema de unidad, admite la necesidad de realizar algunas concesiones. Una

${ }^{29} \mathrm{Al}$ respecto, resulta muy interesante la transcripción de una carta anónima al editor publicada originariamente en el diario inglés The Morning Chronicle, el 24 de noviembre de 1818. En ella se afirma que; "Las provincias del Río de la Plata por más de ocho años han obrado como un Estado independiente. [...] Por tanto ellos constituyen una nación de facto, y deben ser tratados como tal, hasta que vuelvan a sujetarse al yugo de extranjeros." Gaceta, 5 mayo 1819, t. 5, p. 654 .

${ }^{30}$ En relación con el uso de los términos "federación" y "confederación" en los textos políticos del periodo, en la historiografia argentina y en la literatura política europea previa a la experiencia del constitucionalismo norteamericano, José Carlos Chiaramonte nos llama la atención respecto del uso indistinto de los mismos. "Hasta el momento en que la Constitución de Filadelfia inaugurara esa forma inéditi de resolver el dilema de la concentración o desconcentración del poder que conocemos como federalismo norteamericano $-\mathrm{y}$ que da origen a la aparición de un nuevo sujeto de Derecho Internacional, el Estado federal-, los tratadistas políticos, desde la antigüedad hasta el siglo xvin sólo conocían una forma de federación, la confederación - unión de Estados independientes-y a ella se referían con exclusividad cuando abordaban el tema del federalismo." Chiaramonte, Mito, 1991 , p. 27. 


\section{SECUENCIA}

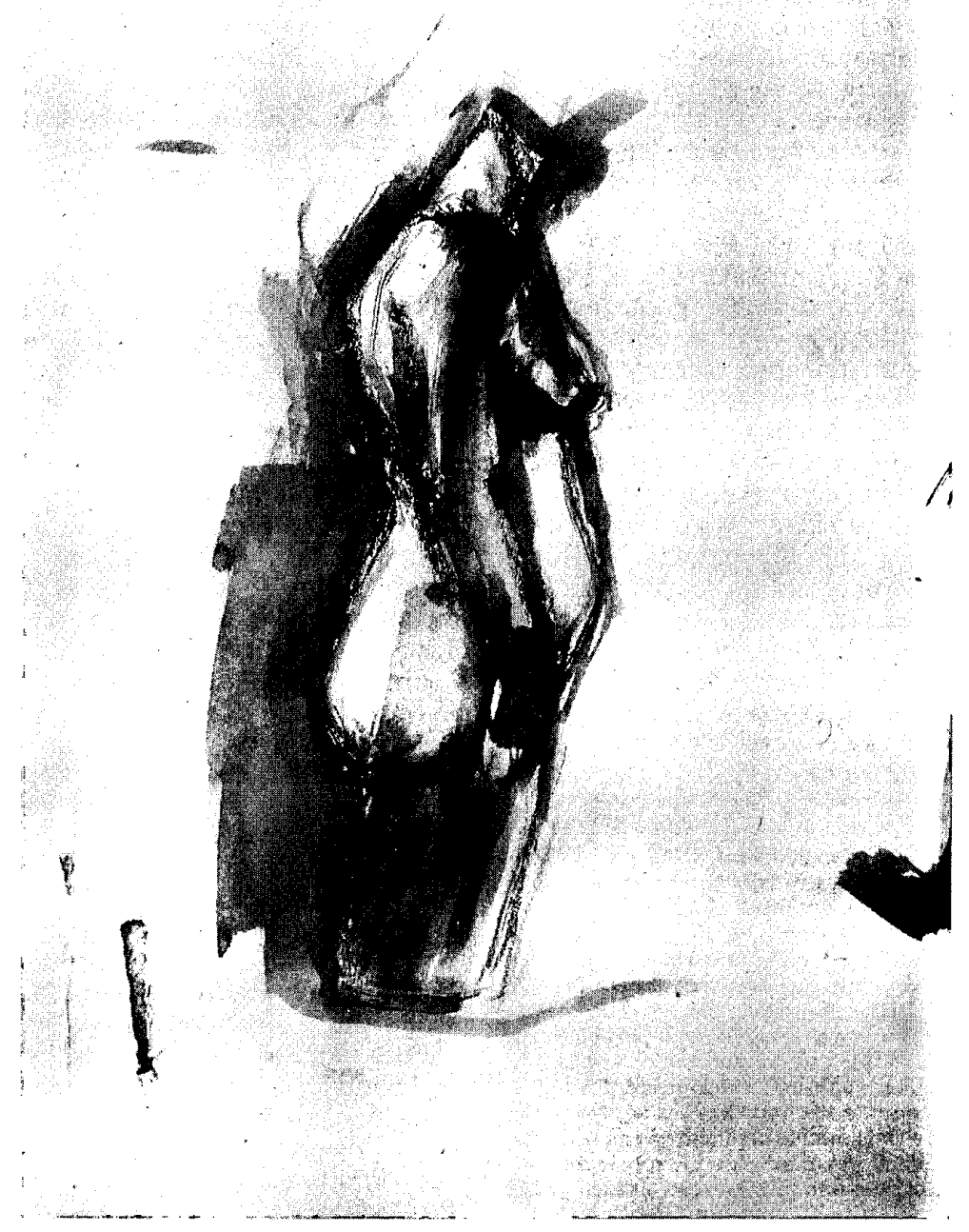


de ellas es la posibilidad de que cada pueblo elija sus representantes, aunque la base para establecer su número sea la población (un diputado por cada 15000 habitantes) y no la condición de "pueblo". Se recurre así a un argumento derivado del principio de soberanía nacional.

Pero se observa por adelantado que aun aquellos que creen conveniente el establecimiento de un sistema unitario, no ignoran las resistencias de los pueblos a su funcionamiento. La tensión entre los derechos e intereses de los pueblos y los de la nación ${ }^{31}$ constituye así un tema recurrente y un rasgo característico de los discursos parlamentarios sobre la formación del nuevo Estado en el espacio rioplatense. ${ }^{32}$

A pesar de las reservas sobre el sistema de unidad, el Congreso de 1816 1820 sanciona una constitución centralista con resabios estamentales que es rechazada por las provincias. En febrero de 1820 cae el gobierno directorial y se disuelve la Asamblea en virtud de la victoria de caudillos de las provincias de Santa Fe y Entre Ríos en la batalla de Cepeda.

31 Gaceta, 20 diciembre 1820 , t. 6, p. 322.

32 "En la necesidad de preferir un sistema de concentración, y unidad, como más análogo a las circunstancias del país, que el de provincias o Estados confederados, dicta la política que se quite a los pueblos el principal motivo de inclinación al federalismo, conciliando en lo posible las ventajas de una administración propia y particular con que éste los lisonjea con otras más importantes que asegura el gobierno de unidad. Ya que no puede concedérseles aquélla, debe dejarse a cada pueblo algún influjo en la legisla. tura general por medio de los representantes que elija cada uno, y merezcan su confianza." Redactor, 1916, 15 noviembre 1818, p. 205.

\section{Nación y soberanías autónomas}

La caída del poder central representado por el Directorio, llevó al desmembramiento de provincias-intendencia y al surgimiento de nuevas provincias en los límites de las antiguas ciudades con cabildo. En la mayoría de éstas se elaboró una constitución en que la so. beranía urbana, imperante desde el quiebre del lazo colonial, dio paso a una soberanía provincial a través de la incorporación de representantes de las respectivas campañas a sus organismos legislativos.

En la medida en que estas provincias fueron resultado del proceso de participación política para definir un nuevo régimen representativo, no es posible considerarlas ni como prolongación de la antigua provincia de intendencia del periodo borbónico, ni como reformulación posterior a 1810. Por lo contrario, estos nuevos espacios políticos soberanos emprenden, a partir de 1820 , una vida autónoma sin por ello abandonar los intentos de una unidad mayor.

En diciembre de 1824 y por iniciativa de la provincia de Buenos Aires, se reunió un nuevo Congreso General Constituyente con sede en la ciudad. puerto. Razones diversas impulsaron al gobierno de Buenos Aires a gestionar su convocatoria ante las demás provincias, entre ellas, la probable firma de un tratado con Gran Bretaña que reconocería la independencia de las Provincias Unidas. La acuciante situación de la Banda Oriental, invadida por los portugueses desde $1816 \mathrm{e}$ incorporada al imperio lusitano como "Provincia Cisplatina" en 1821, cons- 
tituyó otra de las razones. Luego de la expedición de los 33 orientales en abril de 1825 , un congreso reunido en Florida proclamó la reincorporación de la Banda Oriental a las Provincias Unidas. La aprobación de la misma por el Congreso desencadenó un enfrentamiento armado con el imperio brasileño, fruto de su separación de Portugal en 1822.

Tanto la crisis oriental como la guerra juegan un importante papel en la articulación de un discurso sobre la nación que reencuentra un lugar en la prensa y en los debates del Congreso. Es importante destacar el surgimiento en estos años de una serie de periódicos vinculados a la actividad política del Congreso, en que parte de sus redactores son diputados en el mismo. En sus artículos los redactores no sólo vierten sus opiniones sobre los temas debatidos en el seno de la Asamblea, sino que incluso transcriben el contenido de las sesiones. Sin embargo las transcripciones no siempre son fieles al original. La existencia de diferentes versiones de los debates revela la función privilegiada que se asignó a los periódicos, como formadores de una opinión pública en torno a las cuestiones debatidas en el Congreso.

Partiendo de los estudios clásicos sobre el tema, la historiografia argentina insistió en considerar a este periodo como el de un enfrentamiento entre la elite porteña ilustrada unitaria ${ }^{33}$

33 No se sabe con exactitud cuándo surgió la denominación de "unitarios" para aquellos que en ocasión de este Congreso se manifestaron a favor de un sistema de unidad. Lo cierto es que -que buscaba imponer la "unidad nacional" bajo un organismo libre y representativo, usando como instrumento el Congreso y en alianza con los liberales del interior-, y los caudillos, quienes unidos a las masas constituían un obstáculo a la organización de la nación. El error de los unitarios habría residido en su impaciencia al unir dos frentes de lucha que los condujo finalmente a la derrota: la guerra contra el Brasil y aquélla contra los caudillos y partidos reacios del interior. ${ }^{34}$ Este análisis, aunque contiene elementos interpretativos valiosos, descuidó otros que merecen ser tomados en cuenta. Un examen de ciertas argumentaciones en torno al tema de la nación en los debates del Congreso Constituyente y en la prensa que se hace eco de él, revelará que, en su seno, el principio de la soberanía nacional y el de la soberanía de las provincias se enfrentan unas veces y se enlazan otras. Esto no puede sorprendernos si consideramos el proceso abierto a partir de la caída del poder central en 1820. En este sentido es necesario destacar que los problemas implicados en la organización de un Estado rioplatense, partiendo del supuesto de la soberanía de las provincias, no fueron ajenos al mismo discurso unitario. En torno a la conflictiva definición del sujeto del poder constituyente se desplegarán así los temas centrales del debate político del periodo. en el curso de estos años se definen dos tendencias en conflicto: la unitaria (centralista) y la federal (en la que se incluyen también las varian. tes confederales).

${ }^{34}$ López, Historia, 1913, t. IX, pp. 296-298. 
Las nociones de nación en el debate constitucional

En el Congreso Constituyente de 18241827 la cuestión sustancial de si hay o no nación en el momento de su instalación es tema recurrente en los debates. Las discrepancias entre los diputados se van a hacer evidentes en el momento de definir al sujeto de imputación de la soberanía.

Pero es necesario subrayarante todo que hubo un conjunto de concepciones compartidas tanto por provincianos como por porteños, por unitarios y por federales. Estas concepciones pudieron tener diversos orígenes: desde la formación doctrinal ecléctica de los diputados, hasta las fuertes resistencias de las provincias a resignar derechos y privilegios sustanciales. ${ }^{35}$ Así observamos que el conjunto de los diputados parten de un principio común: el origen pactado de la nueva nación. En 1810 con la revolución, las provincias establecieron un pacto de unión que una fatalidad rompió en 1820 y el Congreso viene a restituir ahora.

En 1825 se desarrolla un intenso debate en torno a la propuesta de los unitarios de crear un ejército nacional antes de sancionar la constitución. El portavoz de los defensores del proyecto es el diputado unitario Julián Segundo de Agüero, quien sostiene -fren-

35 En la prensa la dificultad se vislumbra a través de la distinción establecida entre intereses particulares de cada una de las provincias e intereses generales de la nación. Es más, se teme una probable contradicción entre ambos. Véase El Argentino, 24 diciembre 1824, p. 15; ElMensajero Argentino, 4 noviembre 1826, pp. 2-3. te a los que se oponen a la propuesta con el argumento de que no existe aún nación constituida-, que "todos los pueblos del mundo, cuando empiezan a tratar de darse constitución, se consideran como nación, y por lo mismo tratan de organizarse bajo leyes constitucionales". ${ }^{36}$

Juan Ignacio Gorriti, diputado por el interior y opositor al proyecto, luego de afirmar que una nación es una sociedad que se rige por "una misma ley" y un "mismo gobierno", se pregunta:

¿qué cosa es una nación libre? Es una sociedad en la cual los hombres ponen a provecho en común sus personas, propiedades, y todo lo que resulta de esto [...] Cuando ceden y ponen a beneficio de la sociedad esta porción de bienes, es porque las consideraciones con que ellos las ceden y las condiciones que exigen son más ventajosas al individuo, que la conservación de sus derechos plenos en el estado de la naturaleza. Es pues en este sentido que yo he dicho, y repito, que no tenemos nación. ${ }^{37}$

Mientras Agüero hace prevalecer el supuesto liberal de la existencia de una voluntad nacional como fundamento de la constitución del gobierno, Gorriti insiste en la identificación entre forma de gobierno y nación. Agüero se acerca, sin embargo, a Gorriti cuando esboza su propia definición de nación:

Las naciones se constituyen de varios modos por el pacto que forman todos

36 Ravignani, Asambleas, 1937, t. 1, p. 1319.

${ }^{37}$ Ibid, p. 1325. 
los individuos que las componen; y en este sentido nadie puede dudar de que componemos nosotros una nación; porque no hay un ciudadano perteneciente a estos estados que no haya clamado por formar una nación, y un Estado, cada uno a su modo pero todos empeñados en formar un Estado, y en pertenecer a un Estado, y por eso han mandado sus diputados al Congreso y los diputados reunidos con el mayor celo [...] han celebrado un pacto solemne desde el principio de su instalación, de formar una nación libre $e$ independiente $y$ sostener esta libertad $e$ independencia a costa de los mayores sacrificios. ${ }^{38}$

Así, en los significados de nación expuestos por los dos diputados se puede observar, en grado diverso, la superposición de elementos extraídos tanto del iusnaturalismo ${ }^{39}$ como del pensamiento liberal. ${ }^{40}$ Pero lo que importa destacar aquí es que en sus argumentaciones persisten dos rasgos que serán comunes al resto de los repre-

38 Ibid., p. 1320.

39 Cabe recordar que el curso dictado en la Universidad de Buenos Aires durante los años 1822-1823 estuvo a cargo de su primer rector, el Dr. Antonio Sáenz, y llevó como título: "Las instituciones elementales sobre el Derecho Natural y de gentes". En el libro segundo, capítulo 1 de la obra, se lee lo siguiente: "La sociedad lla. mada así por antomomasia se suele también denominar nación y Estado. Ella es una reunión de hombres que se han sometido voluntariamente a la dirección de alguna suprema autoridad, que se llama también soberana, para vivir en paz, y procurarse su propio bien y seguridad." Sáenz, Instituciones, 1939, p. 61.

${ }^{40}$ Sièyes en su célebre opúsculo se preguntó: "Qu'est-ce qu'une nation? Un corps d'associés vivant sous une lot commune et représentés par la même législature, etc." Sièyes, Tiers-Etat?, 1988, p. 40 (redondas del autor). sentantes. Por una parte, la nación no remite ni a un pasado histórico ni a un pasado étnico, ${ }^{41}$ se constituye sólo por la voluntad de sus asociados. La nación aparece claramente como asociación a Estado, congreso, constitución $y$ forma de gobierno. ${ }^{42}$ Por la otra, aunque en un sentido abstracto se conciba a la nación como producto de la asociación de individuos libres, éstos son, en virtud del pacto que reinstaló al Congreso, los habitantes de las provincias. Agüero se preguntará en otra ocasión: “¿Qué es la nación?, ¿es la reunión de todas las provincias bajo un centro común?"43

${ }^{41} \mathrm{Al}$ respecto Chiaramonte llamó la atención sobre la distancia que media entre esta concepción de la nación, que privilegia los intereses específicamente políticos, de aquella difundida más tarde por el Romanticismo, en la cual predomina una valoración del pasado y de las tradiciones. Mito, 1991, pp. 18-24.

42 En otro momento de la misma discusión sobre la creación de un ejército nacional, Gorriti señala: "Señor, para investir el carácter de nación se necesita de algo más dígase lo que se quiera. El Congreso pasado dio en efecto el carácter de nación, aunque por desgracia no tuvo suceso. Diga el señor diputado que subsiste la forma de gobierno que el Congreso dio al Estado, y entonces yo confieso que hay nación." (Ravignani, Asambleas, 1937, Debate, t. 1, p. 1335). Agüero afirma, por su parte, en otra circunstancia: "Señor, si hemos de ser nación es necesario que haya Congreso; y si ha de haber Congreso, es preciso que se hagan sacrificios y erogaciones para sostener a los diputados. $\mathrm{Si}$ éstas no se hacen, no puede haber Congreso, $y$ es imposible que formemos una nación libre regida por la forma de gobierno que hemos adoptado, como la única que pueda garantizar la libertad del hombre en el orden social", Ravignani, ibid., t. 2, p. 264.

${ }^{43}$ Ibid., p. 675 . La prensa política también aborda frecuentemente el tema del pacto de unión como lo muestra este fragmento de unas. 

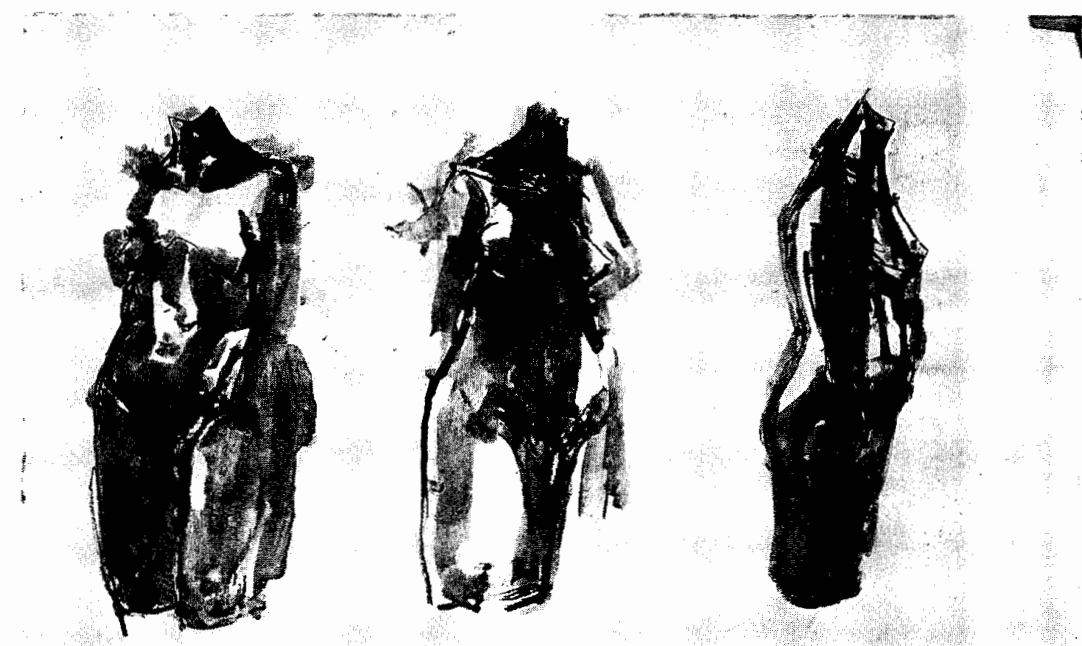

Este concepto de nación como pacto entre provincias nos es ya familiar, pues nos remite a ese principio corporativo de carácter territorial que dio origen a la revolución, tan presente en los discursos de 1810-1813. Pero los sucesos acaecidos en 1820 crearon en

reflexiones del Argos sobre la anexión de la Banda Oriental a Portugal: "Es una verdad sin réplica que desde que las provincias del río de la Plata arrancaron el cetro despótico de las manos del realísimo, y se emanciparon de la España, ellas formaron un pacto social de permanecer unidas. Extendido este pacto, $[\ldots]$ quedaron hechas en su virtud una nación libre e independiente. Por una consecuencia de este principio, cada una de estas provincias quedó sujeta a la autoridad del cuerpo entero en todo aquello que podía interesar al bien común." Argos, 15 enero 1823, t. III, p. 19. Reflexiones sobre la in corporación de la Banda Oriental a Portugal. el conjunto del territorio una realidad nueva, que no es desconocida por el discurso unitario. 44

Sin embargo, esto no impide que en otros momentos los unitarios sostengan con vehemencia la preeminencia de la soberanía nacional por encima de la soberanía de las provincias. En efecto, lo que subyace en los debates es una definición conflictiva de la soberanía. Los enfrentamientos entre unitarios y federales sobre la propiedad de las tierras que van a ser hipotecadas en garantía de la deuda nacional, aportan al respecto elementos valiosos para una mejor comprensión de esta cuestión.

44 Véase Ravignani, Asambleas, 1937, t. 2 , pp. 162-163. 
Lo que entra en polémica es el artículo 6 de la ley de consolidación de la deuda interior del Estado, ${ }^{45}$ a saber si las tierras públicas son de propiedad de la nación o de las provincias. Agüero, en su carácter de ministro de Gobierno, defiende la propiedad nacional de las tierras y para ello recurre a la historia de las Provincias Unidas:

Por una fatalidad los vínculos de unión que componían la nación se disolvieron y la nación dejó de existir de hecho [...] Las provincias entraron, como era consiguiente, en el ejercicio de aquel poder que imperiosamente reclamaban y la necesidad de proveer a su conservación, a su seguridad y a su defensa [...] Así se han conservado hasta que ha llegado la época feliz en que han podido cumplirse los votos de los pueblos, restablecido los vínculos que se habían roto, y vuelto a reorganizarse el Estado, a constituirse una representación nacional y un gobierno general. ${ }^{46}$

De modo que para el ministro las tierras nunca dejaron de ser propiedad de la nación, y quedaron sólo "en depósito" de las provincias durante el tiempo en que permanecieron independientes. El diputado por Buenos Aires, Manuel Moreno ${ }^{47}$, no comparte esta visión y nos proporciona una versión diferente de la historia de las pro-

\footnotetext{
$45 \mathrm{El}$ artículo enuncia lo siguiente: "Quedan especialmente hipotecados al pago del capital e intereses de la deuda nacional las tierras, y demás bienes inmuebles de propiedad pública, cuya enajenación se prohíbe en todo el territorio de la nación, sin precedente ni especial autorización del Congreso." Ibid., p. 669.

$46 \mathrm{Ibtd}$. pp. 672-673.

17 Manuel Moreno es hermano del ya fallecido secretario de la Primera Junta Revolucionaria, Mariano Moreno.
}

vincias. Al defender la propiedad de las provincias sobre las tierras públicas y bienes inmuebles que se encuentran en todo el territorio, introduce la cuestión sustancial de la soberanía:

Haciendo esta historia, es necesario convenir que las tierras antes de la revolución eran dominio de la corona [...] Hecha la revolución pasaron del gobierno general al gobierno del país; fueron de la soberanía del país [...] Esta soberanía estaba concentrada en un punto bajo el gobierno general, pero esta soberanía se subdividió después en las provincias; esto es preciso conocerlo; no han estado nuevamente aisladas las provincias, sino en uso completo, sean los sucesos cuales fuesen, y la consecuencia que debe sacarse: $e l$ hecho es que cada provincia quedó en uso completo de su soberanía... 48

Sin entrar aquí en la extensa discusión sobre la forma de gobierno, lo cierto es que al plantear el problema en términos de la calidad soberana de las provincias, Moreno reconoce la naturaleza jurídico política que poseen en el momento de la reunión del Congreso. Por ello, en otro momento de su intervención, tomando el ejemplo de Estados Unidos, se refiere a las provincias como "estados". ${ }^{49}$ En el curso de los debates otros diputados hacen mención al "cierto estado de federación" ${ }^{50}$ en que se encuentran de hecho las provincias, e incluso llegan a considerar a la reunión de los diputa-

\footnotetext{
48 Ravignani, Asambleas, 1937 , t. 2, pp. 678 679. Cursivas nuestras.

49 lbid., pp. 670-671.

${ }^{50}$ Ibid., p. 163. Intervención de Manuel A. Acevedo.
} 
dos en el Congreso como la de un simple "cuerpo de agregación". 51

\section{CONCLUSIÓN}

La idea de nación en los orígenes de la revolución, que hemos estudiado a través del conjunto de los usos del vocablo en la prensa política de la época, se vincula con un aspecto territorial concreto. Su empleo como suma exacta de sus partes, como unión de pueblos, constituye otro de sus rasgos principales. Observamos por otra parte que la expresión "nación argentina" está ausente del discurso político de estos primeros años.

Un desplazamiento de importancia se produce con la declaración de la independencia de las antiguas provincias del virreinato. A partir de 1816 "nación" se asocia frecuentemente a Estado y a Provincias Unidas del Río de la Plata. Sin embargo, sabemos que un conflicto entre los derechos e intereses de los pueblos y los de la nación surge ya con la primera asamblea constituyente de 1813 ,y adquiere una relevancia particular con la disolución del poder central en 1820.

Por ello, la reflexión política y doctrinal sobre las implicancias de esta tensión para el ordenamiento de un Estado en los debates constitucionales de 1824-1827, pone al descubierto coincidencias y divergencias respecto al concepto de nación. Aquí es digno de destacar el hecho de que tanto unitarios como federales parten del Paso.

51 Ibid., p. 1001. Intervención de Juan José supuesto de la existencia de una nación surgida de un pacto de unión entre los pueblos. Ahora bien, mientras para los unitarios la creación de un gobierno central en 1810 era ya el fundamento de una soberanía nacional, para los federales la caída del poder central en 1820 significó la recuperación por parte de cada una de las provincias, del uso completo de su soberanía, antes sólo depositada en el poder central.

En relación con este tema, en la presente discusión historiográfica sobre Hispanoamérica el tránsito a la modernidad es considerado un gran dilema, cuya comprensión resulta ineludible para aprehender en toda su complejidad el proceso que se inicia a comienzos del siglo XIX. A una concepción monista de la soberanía compartida por gran parte de la elite liberal criolla, se opuso una idea y una práctica pluralistas de la soberanía, que la crisis imperial de 1808-1810 contribuyó a reforzar. ${ }^{52}$ Así, la soberanía de cada uno de los pueblos -concebidos éstos como preestatales-se contrapuso en las nuevas repúblicas a la soberanía del pue. blo o de la nación en sentido abstracto.

Pero el dilema con el que se enfrentaron los unitarios rioplatenses fue en cierto sentido diferente. En efecto, a partir de 1820 el estatus jurídico político de los pueblos (la ciudad y su jurisdicción) rioplatenses tiende a variar de naturaleza. Las nuevas provincias, al adoptar ciertas formas republicanas representativas de gobierno y al ejer. cer atribuciones soberanas, siguen só-

52 Guerra, Modernidad, 1992 y Annino, "Soberanías", en Annino et al., Imperios, 1994, pp. 229-253. 
lo parcialmente organizadas en torno a la defensa de los derechos tradicionales de ciudad. En este sentido, la singularidad del caso rioplatense se manifestó con la temprana supresión de los cabildos y la creación de legislaturas con representación urbana y rural. Y esto explicaría justamente la tensión que atraviesa al propio discurso unitario, cuando sośtiene el principio de la soberanía nacional y al mismo tiempo reconoce que ésta surgió de un pacto de unión entre pueblos.

\section{Bibliografía}

-Anderson, Benedict, Imagined Communities, Verso, Londres, 1983.

-Annino, Antonio, "Soberanías en lucha", en Antonio Annino, Luis Castro Leiva, François X. Guerra, De los imperios a las naciones: Iberoamérica, IberCaja, Zaragoza, 1994.

-Argos de Buenos Aires, reimpresión facsimiliar, Biblioteca de la Academia Nacional de la Historia, Buenos Aires, 19311942,5 vols.

-Baker, Keith Michel, Roger Chartier, "Dialogue surl'espace public", Politix, Presses de la Fondation nationale des sciences politiques, París, 1994, núm. 26, pp. 5-22.

-Chiaramonte, José Carlos, "La cuestión regional como cuestión nacional en América Latina", en Marco Palacios (comp.), $L a$ unidad nacional en América Latina, del regionalismo a la nacionalidad, El Colegio de México, México, 1983, pp. 51-85.

Río de la Plata luego de $1810^{\prime}$, Boletín del Instituto de Historia Argentina y Americana Dr. E. Ravignani, 1989, 3a. serie, núm. 1, pp. 71-92. , El mito de los orígenes en la historiografía latinoamericana, Instituto de Historia Argentina y Americana Dr.
Emilio Ravignani, Facultad de Filosofia y Letras-Universidad de Buenos Aires, Buenos Aires, 1991 (Cuadernos del Instituto Ravignani, 2).

"Ciudad, Provincia, Nación: las formas de identidad colectiva en el Río de la Plata colonial", Actas del III Congreso Argentino de Hispanistas, España en América y América en España, Facultad de Filosofia y Letras-Universidad de Buenos Aires, Buenos Aires, 1992, vol. 1, pp. 101-128.

"El federalismo argentino en la primera mitad del siglo xix", en Marcello Carmagnani, Federalismos latinoamerica. nos: México, Brasil, Argentina, El Colegio de México, FCE, México, 1993, pp. 81-127. -El Argentino (1824-1825).

-El Redactor del Congreso Nacional (1816-1820), reimpresión facsimilar, Imprenta y Casa Editora Coni, Buenos Aires, 1916.

-El Mensajero Argentino (1825-1827).

-Equipe "18 ème et Revolution", Dictionnaire des usages socio-politiques (1770-1815), Publications de l'INaLF, Klincksieck, Paris, 1985-1991, 5 vols. (Collection "Saint-Cloud").

-Gaceta de Buenos Aires, (1810-1821), reimpresión facsimilar dirigida por la Junta de Historia y Numismática Americana, Buenos Aires, 1910-1915, 6 vols.

-Gellner, Ernest, Nations and nationalism, 1983.

-Guilhaumou, Jacques, "A propos de l'analyse de discours: les historiens et le tournant linguistique", Langage et Société, núm. 59, marzo de 1992, pp. 5-38.

Denise Maldidier, y Regine Robin, Discoursetarchive, Mardaga, Lieja, 1994.

-Goldman, Noemí, El discurso como objeto de la historia. El discurso político de Mariano Moreno, Hachette, Buenos Aires, 1989.

, Historia y lenguaje. Los discursos de la Revolución de Mayo, Centro 


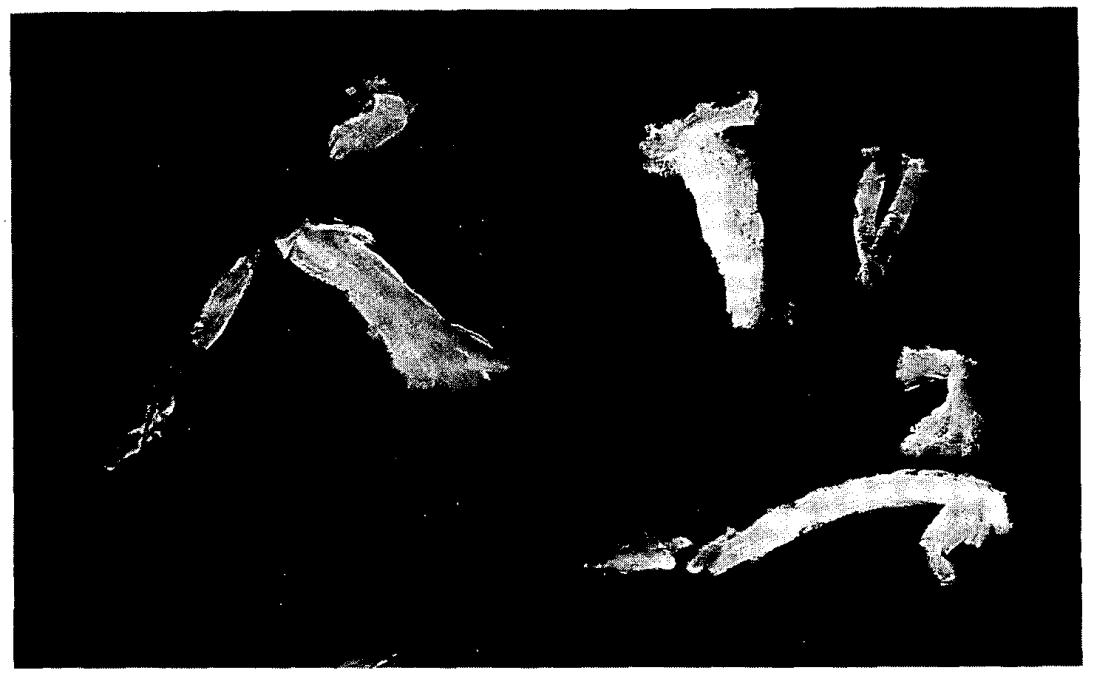

Editor de América Latina, Buenos Aires, 1992.

-Guerra, François Xavier, Modernidad $e$ independencias. Ensayos sobrelas revolucioneshispánicas, Mapfre, Madrid, 1992.

-Hobsbawm, Eric, Nations and nationalism since 1780. Programme, mith, reality, Cambridge University Press, Cambridge, 1990.

-López, Vicente Fidel, Historia de la República Argentina, Kraft, Buenos Aires, 1913,10 vols.

-Ravignani, Emilio, Asambleas Constituyentes Argentinas, Peuser, Buenos Aires, 1937-1939, 7 vols.

, Clave para los ejercicios car. tográficos de historia argentina, Kapelusz, Buenos Aires, s.a.

-Rosenblat, Ángel, El nombre de la Argentina, Eudeba, Buenos Aires, 1964.

-Sáenz, Antonio, Instituciones elementales sobre el derecho naturaly de gentes,
Facultad de Derecho y Ciencias Sociales, Buenos Aires, 1939 (Colección de Textos y Documentos para la Historia del Derecho Argentino I).

-Senado de la Nación, Biblioteca de Mayo, Buenos Aires, 1960-1966, 19 vols. (Colección de Obras y Documentos para la Historia Argentina).

-Sièyes, Emmanuel Joseph, Qu'est-ce que le Tiers-Etat?, Champs Flammarion, París, reed.; 1988.

-Schöttler, Peter, "Historians and discourse analysis", History Workshop, Issue 27, primavera de 1989 , pp. 37-65.

-Souto, Nora, "Nación, pueblo, patria, provincia, país en la Gaceta de Buenos Aires, 1810-1813", 1990 (mimeo).

-Varela Suanzes-Carpegna, Joaquín, La teoría del Estado en los orígenes del constitucionalismo hispánico (Las Cortes de Cádiz), Centro de Estudios Constitucionales, Madrid, 1983. 